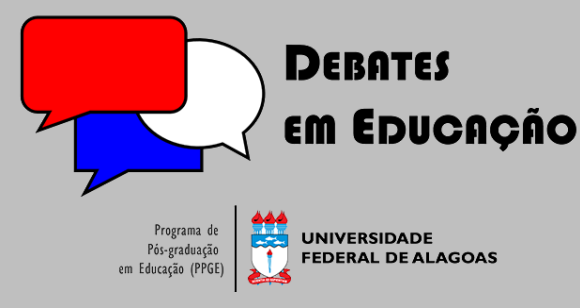

ISSN Eletrônico 2175-6600

Vol. 13 I Número Especial 2 | 2021

Tatiana Zarichta Nichele Eichler

(9) iD

Universidade Federal do Rio Grande do Sul

(UFRGS)

tatiana.nichele@ufrgs.br

Marcelo Leandro Eichler

$\theta$ iD

Universidade Federal do Rio Grande do Sul

(UFRGS)

exlerbr@gmail.com

\section{QUÍMICA E ARTE NO PROCESSO DE CURADORIA EDUCACIONAL}

\section{RESUMO}

Este artigo propõe um convite ao olhar e ao diálogo interdisciplinar entre química, estética e artes plásticas destinados a docentes de Química. Nesse sentido, discute-se a noção de curadoria em suas manifestações no ambiente digital e em relação ao conteúdo educacional. Apresentamse os resultados de uma intervenção pedagógica, proposta aos licenciados em Química da Universidade Federal do Rio Grande do Sul, que tinha o objetivo de realizar um exercício de curadoria com imagens, que reportassem à química, distribuídas na rede social Pinterest. As expografias produzidas pelos estudantes foram analisadas a partir de elementos da semiótica discursiva de Greimas, com ênfase nos quatro elementos constitutivos da natureza: água, ar, fogo e terra. Os resultados mostram que a curadoria realizada no Pinterest pode ser abordada como uma estratégia pedagógica, como uma atividade conducente para os processos de ensino e aprendizagem de estudantes.

Palavras-chave: Curadoria educacional. Ensino de química. Greimas. Pinterest.

\section{CHEMISTRY AND ART IN THE EDUCATIONAL CURATOR}

\begin{abstract}
This article proposes an invitation to interdisciplinary dialogue between chemistry, aesthetics and plastic arts. In this sense, we discussed the notion of curatorship, presenting its manifestations in relation to the digital environment and educational content. We present the results of a pedagogical intervention in which we invited graduates in chemistry to perform a curatorial exercise with the images distributed on the social network Pinterest that were related to chemistry. We analyze the expographies produced by students from elements of Greimas' discursive semiotics, with an emphasis on the four constituent elements of nature: water, air, fire and earth. The results show that curating by Pinterest can be approached as a pedagogical strategy, as an activity conducive to the teaching and learning process.
\end{abstract}

Keywords: Educational curation. Chemistry education. Greimas. Pinterest.

Submetido em: 11/10/2021

Aceito em: 11/10/2021

Publicado em: 30/11/2021

d https://doi.org/10.28998/2175-6600.2021v13nEsp2p216-243 


\section{INTRODUÇÃO}

A curadoria parece ter se tornado um modismo nos dias atuais. Antes restrita às práticas de poucos especialistas, atualmente aplica-se a praticamente tudo. Organizadores e profissionais de festivais de música, lojas e shoppings centers, sites de todos os tipos, jornalismo, palestras sobre Tecnologia, Entretenimento e Design (TED talks), carteiras de investimento, cerimônia de inauguração, jantares, playlists, férias, identidades pessoais, desfiles e cartas de vinho alegam trabalhar por meio de um processo de curadoria. A curatela se tornou uma moda porque é a resposta para uma série de problemas que antes não existiam: os problemas decorrentes do excesso. Hoje, cada pessoa viva tem 320 vezes mais informação à sua disposição do que em toda a biblioteca de Alexandria (BHASKAR, 2020).

Profissionais ligados à área tradicional da curadoria estão descontentes, pois consideram que seja inadequado empregar a palavra de qualquer forma, como se essa prática estivesse envolvida de fato em qualquer processo. Ainda, se pensamos que a curadoria veio do mundo das artes podemos estar enganados. A palavra 'curadoria' vem do latim curare, que significa cuidar e preservar. Além de carinho e nutrir, a palavra significava implicações políticas, posto que, antigamente, curadores eram funcionários públicos responsáveis pela infraestrutura e por outras atividades, como jogos públicos e o tráfico fluvial no Tibre 1 .

Nesse contexto, os museus costumavam ser ambientes estáveis e seguros para guardar, cuidar e preservar elementos variados e preciosos, e a pressão de selecionar o que exibir aumentou à medida que esses espaços se voltaram às exposições temporárias. Tal fenômeno é de tamanha significância porque, por isso, o termo adquiriu, pouco a pouco, um uso mais amplo fora das artes. É uma palavra útil para muitos elementos que já existiam numa variedade desconcertante de contextos, contudo, o processo de organizá-los só começou a ser chamado de curadoria porque a palavra estava ao alcance.

"A curadoria é decorrente da abundância" (FLORIDI, 2018). Assim, é simples entender como se tornou parte da internet, já que a curadoria online não relaciona-se apenas com a redução/organização de bens, mas também com uma análise qualitativa em meio a distrações bem mais delicadas. O processo curatorial evidentemente não é a salvação para sanar o problema da falta de tempo, do excesso de atividades que temos

\footnotetext{
1 O Tibre (em italiano: Tevere; em latim: Tiberis) é um rio no território italiano, com nascente na Emília-
} Romanha. Atravessa a Toscana, a Úmbria e o Lácio (inclusive a capital Roma), e desagua no mar Tirreno. 
para realizar, porém, favorece uma abordagem que não aumenta a sobrecarga, mas efetivamente a diminui e auxilia a atravessá-la e navegar pela nova fase da economia.

Nesse cenário, este artigo visa apresentar uma discussão acerca do diálogo interdisciplinar entre química, estética e artes plásticas. Não obstante, discutimos a noção de curadoria nas manifestações do ambiente digital e em relação ao conteúdo educacional, assim como apresentamos os resultados de uma intervenção pedagógica realizada com licenciandos em Química da Universidade Federal do Rio Grande do Sul.

\section{CURADORIA: UMA VISÃO GERAL}

O trabalho de muitos profissionais curadores, nos dias atuais, é justamente saber no que prestar atenção, saber selecionar e/ou refinar informações, diante disso que se compreende o valor dessa área. Num mundo onde há tantos dados disponíveis virtual e digitalmente, é imprescindível que eles sejam verificados, com qualidade, agilidade e eficácia, com o objetivo de compreender se são corretos e/ou válidos, já que o tempo que se pode perder nesse processo é precioso. Logo, o papel importante do curador é tomar a atitude certa, a qual poupará tempo e irá focalizar, organizar as ideias, os fados, as buscas etc. (MAYER-SCHÖNBERGER; CUKIER, 2013). Mas, como chegamos nesse contexto?

A Revolução Industrial promoveu uma produtividade desenfreada, em que objetos e materiais que sempre foram escassos passaram a estar disponíveis. Desse modo, a resposta direta para a pergunta de como chegamos ao contexto em que temos tudo em excesso é que a produtividade vem aumentando há mais de 200 anos. De acordo com Harari (2018), a subjugação das forças da natureza, as máquinas, a aplicação da química na indústria e na agricultura, a navegação a vapor, as estradas de ferro, o telégrafo elétrico, a exploração de continentes inteiros, a canalização dos rios, populações inteiras brotando da terra como por um encanto promoveram, por meio do seio do trabalho social, estas semelhantes forças produtivas, que estiveram adormecidas.

A tecnologia sempre teve papel crucial nas mudanças. A Revolução Industrial foi impulsionada pelo tear mecânico e pela máquina a vapor, símbolo dessa primeira revolução. No entanto, 100 anos depois, a segunda revolução industrial, menos conhecida que a primeira, novamente revelou como a tecnologia transforma a produtividade constantemente. Werner von Siemens (1816-1892) criou o gerador auto excitado, um dínamo que converte energia mecânica em energia elétrica, e se há uma invenção que caracterize a segunda revolução industrial, essa é o gerador elétrico. 
Nessa época, também, compostos químicos e corantes sintéticos, por exemplo, foram desenvolvidos por empresas alemãs como a Fábrica de Anilina e Soda de Baden (BASF) e a Bayer, que por meio de pesquisas produziram esses compostos em larga escala. Além disso, houve uma infinidade de outros avanços técnicos: a produção da dinamite; o uso de borracha e lubrificantes para facilitar e acelerar a produção; e a introdução de fertilizantes nitrogenados, os agrotóxicos, na agricultura.

Éramos aproximadamente 600 milhões de habitantes por volta de 1700. Atingimos 1 bilhão de pessoas em torno do ano de 1820. Cem anos depois, a população mundial era um pouco menor que 2 bilhões de habitantes e está atualmente rumo aos 8 bilhões de habitantes.

O desenvolvimento tecnológico e a explosão populacional são manifestações óbvias de como criamos condições para o excesso; a economia é uma expansão das tecnologias (ARTHUR, 2009). Nos últimos 250 anos, nossas tecnologias foram direcionadas para impulsionar a produtividade, para produzir mais, mais bens, mais alimentos, mais dados etc., ou seja, ao longo dos anos, criamos condições para o excesso: a tecnologia gera melhorias na produtividade, que gera crescimento econômico, que leva a uma demanda maior de produção e de transformação tecnológica e assim sucessivamente. Ao acrescentar isso a uma população que está em constante crescimento e que dá ênfase cada vez maior à obtenção do máximo lucro possível, teremos as condições para a expansão contínua.

Os efeitos negativos dessa expansão já são sentidos, por meio do acúmulo de dados, roupas, sapatos, maquiagem etc. Isso porque, com as revoluções industriais e tecnológicas, produzimos e adquirimos muitos mais bens do que precisamos. Em muitos aspectos das nossas vidas, em virtude da combinação de crescimento econômico e tecnológico, a escassez deu lugar à abundância, muita gente tem uma ou outra coisa em quantidade excessiva, e é aí que entra a curadoria.

De qualquer modo, curadores tinham acesso e domínio aos conhecimentos difíceis ou ocultos. Por exemplo, o Museu do Louvre, em Paris, foi inaugurado após a Revolução Francesa, em 1793. O Louvre empregou, desde o início, uma nova proposta: concebido como museu para o povo e do povo, foi simbolicamente posicionado no palácio do centro do ancien régime, entregue à edificação das massas. Com Napoleão Bonaparte - que chegou a batizá-lo de Musée Napoleón em 1803 -, o Louvre recebeu um novo impulso através da pilhagem proveniente das capitais europeias pelo militar conquistadas. Por volta dessa época, o diretor Dominique Vivant, Barão de Denon, tomou outra atitude em relação ao enorme aumento da quantidade de obras da coleção: ao invés de exibir obras em 
desordem total, como era comum, as organizou e observou a evolução da arte no tempo e no espaço. Ao fazer isso, não apenas definiu o propósito da curadoria e museus ao longo do Século XIX, mas transformou o Louvre, que deixou de estar associado à revolução para se ligar à apreciação e ao entendimento da história da arte (SCHUBERT, 2009). Curadoria, portanto, não significa apenas cuidar de elementos, mas selecioná-los com uma finalidade específica, com vistas a dispô-los de maneira a contar uma história.

Assim como a Revolução Industrial transformou o significado de produtividade, a arte também teve seu significado transformado. Daí a ascensão do curador: era ele quem lia tudo, dizia o que era arte, explicava porque ela era importante e dava sugestões sobre o seu valor. O caráter das exposições também mudou. Para o bem ou para o mal, os curadores passaram a ser, de fato, os papas da arte.

Se a tecnologia computacional ou a microeletrônica representam a terceira revolução industrial (SCHAFF, 1992), são plantadas as sementes para quarta com o processo curatorial. Mas o que isso tem a ver com a curadoria atual? Diante desses questionamentos, cabe ressaltar que o crescimento econômico e o tecnológico representam um bom acontecimento. A abundância, geralmente, é algo positivo, já que significa uma qualidade de vida jamais imaginada. Nos anos 1990, a internet era limitada, mas a web transformou isso e levou a conexão ao alcance de milhões, e, de repente, havia conteúdo em tudo, praticamente grátis e com poucas barreiras para criação. Da mesma forma como Danon, no Louvre, visitantes ou empresas comuns viram-se diante de um amontoado de material no qual teriam que encontrar sentido, para si mesmos e para os outros. Se a web fez de todos nós criadores e editores, também nos transformou em curadores. Assim, a curadoria de arte rapidamente metamorfoseou-se em curadoria de conteúdo. É o curador uma espécie de guia num pântano de conteúdo.

A antiga plataforma Geosites ${ }^{2}$ foi uma das primeiras a realizar curadoria de conteúdo. A partir dela constatamos que essa prática não é um suporte para se assistir, é uma atividade que pode ser desenvolvida por milhões, senão bilhões de pessoas. Curador, curadoria e curatorial não são termos estáticos. Apesar dos protestos, do esnobismo e da resistência, a curadoria avançou bastante.

Diante disso, a maioria das empresas não possui 'curadores': não dão, às suas atividades, o nome de curadoria, mas, apesar disso, a realizam. A curatela é algo inerente

\footnotetext{
2 Yahoo! GeoCities foi criado em 1994 como GeoCities, por David Bohnett e John Rezner. Foi um serviço de hospedagem de sites do portal Starmedia, bastante popular no início da década. Foi depois adquirido pelo Yahoo!, mas atualmente não existe mais - o seu serviço foi descontinuado.
} 
à atividade, seja ela comercial, cultural, social ou de negócios, uma vez que esse processo acontece quando as práticas de seleção e arranjo somam valor.

Além dessa definição, existem princípios complementares geralmente presentes na curadoria: refinar, simplificar, explicar e contextualizar. "Não há como ter bens demais" (como de consumo, roupas, aparelhos eletrônicos etc.), é o que muitas pessoas podem pensar, mas, na verdade, não se trata somente de quantidade e sim de ter as informações certas, realmente importantes e de saber tomar as melhores decisões a partir disso. É assim que se consegue avançar.

A sobrecarga de informação é um problema clássico. James Wallman (2015) sugere que também sofremos da sobrecarga de pertences: há um stuffocattion (sufocamento) pelas coisas. O stuffocation se manifesta, inclusive, fisiologicamente, quanto mais tralhas as pessoas têm, maior é o nível de estresse. Ficamos mais impacientes, queremos as coisas agora e do nosso jeito, damos prioridade aos prazeres imediatos e de curto prazo ao invés dos bens de longo prazo. A sobrecarga, o ponto em que a gestão do tempo não é eficiente, não acontece. Parte disso é conhecida como sobrecarga de papéis, por exemplo, a ideia de que aceitamos o número exagerado de tarefas simultâneas (mãe, chefe, funcionária, colega de trabalho, esposa, amiga, irmã, motorista etc.).

Nesse contexto, não conseguimos prestar atenção detalhadamente em uma atividade, como no que fazemos no trabalho, nos estudos, porque falta tempo; porque temos muitas tarefas para realizar. Isso nos impossibilita de pensar, refletir, assentar o aprendizado. Todavia, afinal, de que adianta prestar atenção? Se não temos um momento de reflexão, não aprendemos. Simultaneidade, instantaneidade e conectividade obsessiva retiram o maior combustível da criatividade humana: o tédio. Hoje em dia não há ninguém desocupado, a ausência de tédio permite informação, mas reduz nosso espaço de conhecimento. É preciso ter um momento de meditação, de parar para prestar atenção, tanto que o papel do sono é fixar na memória o que aprendemos (CORTELLA; DIMENSTEIN, 2015). No contexto do excesso, curadoria não é somente modismo. Num mundo de coisas demais é essencial selecionar, escolher e reduzir; na curadoria, menos é mais.

\subsection{Curadoria de Conteúdo}

Por maior que pensemos que a Internet seja, ela só aumenta. Atualmente, está muito além da compreensão, pois estamos entrando na era do yottabyte (1024 bytes). A Deep Web, parcela que fica além do escopo da indexação das buscas, representa $96 \%$ de todos 
os dados digitais, sejam intranets empresariais, sistema de comunicação anônimo Tor ou a darknet das transações criminosas. Temos a sensação de que o conteúdo nos oprime, de que estamos afogados em informação e em notícias. Não se trata apenas de criação, a filtragem de conteúdo também tem seu valor e ela é feita de forma coletiva e com curadoria.

Em termos bem básicos, o processo funciona assim: i) encontrar conteúdo (dos jornais, Twitter, newsletter, leitores de feed, monitoria de palavras-chave, imprensa especializada e focada, usuários relevantes e influenciadores de redes sociais); ii) selecionar e organizar esse conteúdo, o que costuma incluir comentário sobre o trabalho, encaixado em conta ou coleções; e iii) compartilhar as informações com os outros.

A boa curadoria de conteúdo demonstra competência e pode exigir uma seleção feita com inteligência, que em si já é um recurso, mas exige menos tempo inicial. Quando bemfeito, o processo curatorial de conteúdo constrói confiança, é útil e interessante, assim como demonstra que parcerias funcionam com altruísmo como parte de um diálogo mais amplo.

Para Floridi (2018, p. 482), há conotações éticas que remontam à raiz curare:

Curadoria implica responsabilidade por aquilo que você cura [...] Curadores são peritos - é preciso ter voz para ser curador. [...] É o que coloca entidade, coisa curada, no centro. O curador tem uma mentalidade, uma sensibilidade que enxerga o que é bom para tal coisa. O bem dessa entidade vem em primeiro lugar; antes do curador.

Curar não significa apenas selecionar e dispor, significa fazer isso com o propósito de ajudar outrem (BHASKAR, 2020). Centrada na pessoa, é "um processo quarup", uma "cola social", uma troca de informação entre amigos. A curadoria talvez seja valiosa não exatamente porque evita o algoritmo e o agregador, ao invés disso, esses próprios processos automáticos estão imbuídos de valores, idiossincrasias e tudo mais que é humano. Esse processo de maneira automatizada e humana ocorre em plataformas como Amazon, Apple e Netflix, em que os algoritmos contabilizam os "votos favoráveis" humanos ou métricas de envolvimento e nós, por outro lado, reagimos a eles e os moldamos.

O Pinterest, por exemplo, é como a maioria desses serviços: uma mistura. A curadoria pessoal dos usuários enche suas próprias coleções, enquanto o site como um todo usa diversos mecanismos automáticos para encontrar, recomendar e classificar esse material. Assim, os usuários fazem do Pinterest um espaço de curadoria densa - intensa, plena, baseada em opções pessoais com detalhamento -, mas o site construiu sua própria curadoria rasa - curadoria automatizada - para auxiliar seus consumidores. E para aqueles que talvez achem o Pinterest um exemplo trivial, ele tem 416 milhões de usuários, está avaliado em aproximadamente 25 bilhões de dólares, em 2019 gerou pouco mais de 1 
bilhão de dólares em publicidade e tem uma interface de programação de aplicação (API) para grandes usuários comerciais (ASLAM, 2021).

O critério humano de seleção é imprevisível, complicado e delicado, mas pode ir além dessa versão canalizada e automatizada da web. Precisamos de algoritmos que nos auxiliem, entretanto, ainda precisamos de nós mesmos. Em nível mais amplo, sem um misto entre seleção por algoritmo e seleção humana, o equilíbrio de vários tipos de curadoria cairá em circuitos de autorreforço do gosto e da opinião. Em vez de abrir o mundo para ser explorado, a curadoria o fecharia.

\subsection{Curadoria Educacional}

A curadoria educacional permeia caminhos metodológicos que possibilitam que professores e estudantes construam e compartilhem conhecimento de maneira crítica, criativa e dinâmica. Há algumas questões pertinentes neste contexto de discussões: Qual o papel do professor? Aquele que é curador do conhecimento. O que pode ser considerada uma boa escola? Lugar onde o aluno gosta de estar e/ou talvez aquela que possua um projeto pedagógico integrado de rede entre os docentes. Ademais, fazemos coisas que nos emocionam. Em latim, emovere significa "aquilo que mexe com você". Desse modo, o que mexe com o aluno hoje? Com a pessoa? O que a faz se emocionar? Se não conseguimos criar pontes, não vamos conseguir chegar ao outro. Rubem Alves nos lembra: "não é à toa que se chama grade curricular e que quem cuida de escola se chama delegacia [de educação, ou de ensino]" (ALVES, 2001).

Neves (2009) sugere que o projeto pedagógico imaginado por Karl Marx falava sobre omnilateralidade, isto é, formação por todos os lados. Quem educa deve se responsabilizar por oferecer processos educacionais que possam garantir sustentabilidade ao longo da vida. Os estudantes devem ser formados para transformarem-se em sujeitos aprendizes para toda a vida (GARCIA; CZESZAK, 2019a) e esse processo inclui a educação digital. Esses são os indivíduos do Século XXI. Se os educadores são atravessados por uma avalanche de informação, os estudantes também não fogem à regra. Neste cenário, cabe ao professor ter conhecimento e discernimento para realizar uma seleção criteriosa de ferramentas digitais (sites, editores, ferramentas de buscas confiáveis) com vistas a ajudar os estudantes no processo de curadoria educacional e de aprendizado.

A inclusão de ferramentas e conteúdos inovadores na experiência educacional não faz sentido se não houver o objetivo de desenvolver a criticidade, a capacidade de pesquisa e autonomia do estudante para experimentar. Para que isso seja alcançado, o professor (e 
curador) precisa entender os métodos de fazer pesquisa, pois conhecimento e acesso a informações são coisas diferentes. As informações são dados, mas o conhecimento é a relação desses dados com as experiências e vivências. Neste caso, ao selecionar, compilar e distribuir conteúdos, o educador deve estar atento à realidade dos estudantes.

A curadoria digital está em livre desenvolvimento e constitui o termo guarda-chuva, que abarca definições de seleção, enriquecimento, tratamento e preservação da informação. A literatura sobre esse assunto no Brasil ainda é muito escassa, mas se sabe que há uma recente tendência de estudos relevantes sobre o tema, sobretudo no que concerne à curadoria digital.

A escola deve ser um centro de curadoria sofisticado ou pode correr o risco de perder sua importância, pois já é possível o acesso a excelentes aulas fora do ambiente escolar, no YouTube ou sites de podcasts, por exemplo. A sala de aula é uma rede entre alunos, mas não com os docentes. Curar informações para organizar as narrativas cria um senso de responsabilidade para o curador, no caso da escola, o professor (professor-curador). Curadoria seria também um ato de resolução de problemas.

A tecnologia no ambiente educacional tem sido utilizada principalmente como forma de melhorar e facilitar a apresentação e organização da sala de aula (GARCIA; CZESZAK, 2019b). Pode-se considerar que pouco tem sido feito no sentido da estruturação em torno de integração significativa com categorias para capacitar a agência crítica para o futuro digital. A curadoria como alfabetização da mídia digital, nesse aspecto, pode ser inspiradora em torno da análise crítica da informação pelo indivíduo (CORREIA, 2018).

O estudo realizado por Bartlett e Miller (2011) mostra que os estudantes são muito vulneráveis e possuem um excesso de confiança nos conteúdos da web, de modo geral. A natureza rápida da internet geralmente leva ao consumo acrítico e à escolha de sites mais agradáveis em design, esteticamente falando, do que em detrimento do uso da informação em função de sua qualidade (KIILI; LAURINEN; MARTTUNEN, 2008).

A alfabetização midiática crítica, nesse âmbito, pode ser utilizada para combater as estruturas de poder hegemônico na sociedade ao capacitar os alunos a se tornarem pensadores críticos. Com isso, transferiria o poder das mãos dos distribuidores para as mãos dos receptores. A ideia é fomentar o pensamento crítico e diversificado em resposta às simples paisagens midiáticas ${ }^{3}$, que já não se encaixam em estruturas hegemônicas diretas. Estudos mostram que o aumento dos níveis de alfabetização na internet, a

\footnotetext{
${ }^{3}$ Paisagem midiática, mediascape, em inglês, descreve os recursos visuais (imagética) e seu impacto na percepção do mundo. Esse termo foi utilizado pelo antropólogo Arjun Appadurai e o mundo mediascape também descreve a cultura visual.
} 
competência digital e aprendizagem online orientada pode proporcionar melhor qualidade em tempo digital, bem como melhorar a capacidade de análise por parte do usuário (GARCIA; CZESZAK, 2019b).

Existe uma gama de ferramentas na web que podem ser utilizadas para promover curadoria educacional: Facebook, Twitter, YouTube, Pinterest, Instagram, Prezi, Storyful, Amplify, Scoop, entre outras, as quais permitem aos usuários organizar seus perfis de informação em todos os tipos de conteúdo e formatos de mídia. Essas ferramentas, que trabalham com compartilhamento padrão e personalizado, disponibilizam características vantajosas para serem utilizadas no controle de usuários fluídos.

O Pinterest, por exemplo, não compete em número de usuários com redes sociais verticais como o Facebook, nem com redes sociais visuais como o Instagram. No entanto, ele ocupa um nicho significativo equivalente à estante de produtos, sobretudo para aqueles orientados ao desenho, arquitetura, arte, moda e alimentação. O Pinterest, como ferramenta visual, armazena tanto imagens específicas quanto os links de procedência. Assim, podem ser postadas imagens do computador do usuário, utilizadas comercialmente ou para fornecer "inspiração", as famosas imagens "pinteressantes".

Destarte, sugere-se que o Pinterest pode ser utilizado para caracterizar narrativamente as infografias e visualizações no contexto digital. A exploração heurística mediante a ferramenta de descobrimento visual e seu sistema de coleções e pins (imagens) permitem gerar um corpus, uma biblioteca, um banco de dados, uma exposição qualitativa e quantitativa de infografias e visualizações atuais e um segundo corpus mais específico de caráter narrativo (FERRER, 2015).

Essas coleções de pins, que compõem um corpus, uma biblioteca ou um banco de dados, podem ser entendidas como uma expografia. Expografia, expressão utilizada em exposições de artes e ou museológicas, estendida para exposições e/ou coleções virtuais, é o conjunto de técnicas para o desenvolvimento de uma exposição (MARTINEZ, 2007). A expografia, espaço construído física e simbolicamente, constitui-se de três elementos básicos: o conteúdo, a ideia e a forma, os quais, somados, geram a percepção e a experiência estética. Não há exposição sem o trabalho de curadoria e, consequentemente, não há conteúdo de um museu ou galeria sem essa prática.

Nas exposições individuais, quando o conjunto de obras expostas é selecionado a partir de uma única série ou pertence a um único colecionador, a relação entre obra e montagem favorece a unidade geral e a visibilidade equânime. Nas exposições coletivas prevalece a diversidade de formas de montagem, sendo necessário atender às solicitações 
de diferentes artistas e colecionadores, cada um com critérios próprios para que a obra seja devidamente exposta (MARTINEZ, 2007).

Tendo isso em vista, entendemos que o que forma a Ciência não é a eliminação da paixão, sensibilidade e intuição do trabalho diário, mas o aproveitamento desses modos subjetivos de percepção às exigências rigorosas da validação cética ou à prova de elementos. Justamente por isso a imaginação artística ou o design podem fornecer os meios para dar muitos saltos criativos em direção ao imaginante. Os conceitos estéticos são formas de pensar sobre ideias científicas e a experiência sedutora é a base da intuição que trazemos ao nosso trabalho, onde cada um de nós desenvolve uma espécie de "conhecimento pessoal", ou intuição, sobre como a natureza funciona - que vem de nossas interações próprias, sedutoras e íntimas com ela. E mais, há quem sustente a ideia de que os alunos são prejudicados ao se esconder a face sedutora e estética da ciência deles, mas, sem ela, não há motivação ou atração sobre o assunto.

Por isso, sugerimos que os estudantes devam saber que muitos químicos exímios e bem-sucedidos descrevem a Ciência como uma arte e que as considerações estéticas podem motivar não apenas um interesse pela química, mas por problemas e soluções. Dessa forma, no que tangencia à problemática do ensino e da aprendizagem de química, podemos desfrutar de conceitos sedutores, estéticos e artísticos como importantes incentivos para o interesse geral na área da química e para o desenvolvimento de problemas de pesquisa específicos.

É necessário e possível, portanto, dar mais atenção às questões artísticas (sedutoras) e estéticas para entender como as descobertas químicas são feitas e para ensinar melhor o conteúdo. Para alguns, não faz sentido pensar em Química até que se faça alguma prática experiencial. Fórmulas e reações devem se referir a substâncias e processos reais e, para tanto, quanto mais sensuais ou sedutores puder se fazer uma experiência química, mais reais os quebra-cabeças se tornam para as pessoas.

Não obstante, como já salientado anteriormente, este artigo propõe um convite ao olhar e ao diálogo interdisciplinar entre química, design e artes plásticas. Nesse sentido, convidamos aos licenciados em Química e aos professores de Química da educação básica para realizar uma reflexão estética sobre os aspectos sedutores da/na Química por meio de imagens relacionadas à área e distribuídas em redes sociais como o Pinterest. 


\section{METODOLOGIA}

Como sugerido anteriormente, entendemos que com a utilização da rede social Pinterest é possível formar um ambiente, um cenário, que permite empregar um processo de criação de uma didática a partir de um tema, uma obra, um artista, uma disciplina etc. (EICHLER; ARAÚJO; EICHLER, 2017). Com o desenvolvimento e aumento da utilização da informática, da internet e das redes sociais, coexistem, neste universo comunicativo e visual, formas não lineares de contar histórias (interrupções no caminho narrativo), formas multilineares (múltiplos caminhos narrativos) e interativas (intervenção em uma narrativa). A narrativa no contexto digital, por meio de seu "caráter polimorfo", demonstra que pode ser linear ou não, multilinear ou não, interativa ou não, transgredindo tanto aspectos formais como de conteúdo. Isto significa que possui uma estrutura narrativa, em maior ou menor grau, que é digital e que é considerada uma categoria capaz de amalgamar a criação digital contemporânea com elementos narrativos (FERRER, 2015).

Para fins metodológicos, este artigo foi proposto com enfoque dedutivo para classificar as infografias, visualizações e imagens. Assim, são distinguidos os conjuntos de imagens que podem ser considerados como narrativas, ou seja, aquelas imagens que contam histórias (FERRER, 2015). A seguir, descrevemos a tarefa apresentada aos estudantes e, posteriormente, são apresentados e justificados os critérios utilizados na análise das exposições curadas pelos licenciandos.

\subsection{A Tarefa}

Foi realizada uma atividade didática durante dois semestres consecutivos, em duas disciplinas do curso de Licenciatura em Química da Universidade Federal do Rio Grande do Sul: Projetos de Educação Química - Cultura Científica (em 2020/1) e Projetos de Educação Química - Espaços Escolares (em 2019/2). A proposta foi a de que os estudantes fizessem uma reflexão estética sobre os aspectos sedutores da/na Química sobre as imagens da área que estão distribuídas na rede social Pinterest. A atividade consistiu em convidar os estudantes a trilhar pelas veredas da imaginação em representações internalistas (as imagens que os químicos utilizam para pensar) e externalistas (as imagens que são inspiradas pela Química), com o intuito de evidenciar a estética e a sedução da Química. Nesse sentido, foi indicada a leitura de textos que escrevemos e que defendem a curadoria como uma metáfora da docência (EICHLER; EICHLER, 2017; EICHLER; ARAÚJO; EICHLER, 2017). 
Para a realização da tarefa, indicamos que cada estudante deveria: i) criar um perfil de usuário na plataforma Pinterest; ii) escolher um conceito ou tema de seu interesse sobre Química, e iii) criar uma pasta/mostra/exposição em seu perfil na rede social para armazenar o resultado de sua compilação das infografias/imagens.

As infografias/imagens armazenadas deviam ser sobre Química em uma abordagem conceitual (por exemplo, átomo, molécula, ligação química, propriedades coligativas, eletroquímica etc. - que são os conceitos estruturantes da química) ou sobre uma abordagem temática (por exemplo, buscar a Química em temas como alimentos, perfumes, cosméticos, combustíveis etc.). Foi estabelecido que a pasta/mostra/exposição criada no Pinterest devia ser individual (não coletiva) e que devia conter um conjunto de pelo menos 20 imagens/infografias, as quais seriam utilizadas para apresentar, ilustrar ou problematizar o conceito ou tema escolhido.

Além disso, ressaltamos para os estudantes que essa atividade poderia ser estendida e futuramente replicada a outras instituições de ensino e de forma coletiva, por exemplo, em sala de aula, com estudantes do Ensino Fundamental ou Médio.

\subsection{Análise expográfica a partir da semiótica discursiva de Greimas}

Um dos objetivos deste artigo é relacionar o percurso gerativo do sentido das expografias produzidas pelos estudantes com foco no estudo da semiótica discursiva de Greimas (1973). A abordagem greimasiana de experiência estética oferece algumas sínteses que favoreceram a leitura de memoriais de professores e alunos, especialmente a narrativa de encontros estéticos que possam inspirar a organização de práticas pedagógicas com as linguagens das artes. O autor enfatiza a estesia nos momentos de apreensão estética: ao entrar em contato com formantes estéticos há um envolvimento corporal do sujeito que significa o evento do qual participa (GREIMAS, 2002). Dessa forma, ele salienta o aspecto interacional da apreensão estética de mundo, apresentando a discussão de estética para as práticas cotidianas em que sensível e inteligível entretecem sentidos para o entorno. Na visão de Greimas (2002), as experiências estéticas fazem parte de eventos do cotidiano, que também são analisados como possíveis conteúdos de situações de aprendizagem das artes na escola.

Sobre os sentidos e a sensibilidade podemos fazer uma relação com a estética. $O$ que é estética e estético? Podemos fazer uma reflexão inicial sobre a própria origem da palavra em português e em inglês, 'aesthetic'. De acordo com o Dicionário Aurélio (FERREIRA, 2008, p. 121), 'anestesia' significa perda total ou parcial da sensibilidade. Os 
problemas estéticos são tão antigos quanto à própria filosofia (SANTAELLA, 1994). Com respeito à estesia, podemos abordar a experiência do prazer ou desprazer ao valorizar a percepção dos sentidos, da sensualidade e da sensibilidade. Neste caso, destacamos a importância dispensada à "duração", a qual Greimas trata também como "realidade escondida" ou "ser escondido" num contexto em que os sinais da estesia surgem na forma de "parada do tempo" ou "esperança de uma vida verdadeira" (LANDOWSKI, 1999).

A despeito do caráter "cognitivamente inapreensível" da experiência sensível, Greimas orienta não "fechar as pálpebras", mas procurar compreender o modo como ele faz sentido (LANDOWSKI, 2017). Primeira diferença que marca a passagem de uma visão à outra é a apreensão da forma sensível do sentido, por meio da experiência estésica, que não mais será associada exclusivamente a circunstâncias excepcionais, o que produz bruscas descontinuidades. Podemos vivê-la também nos "nossos comportamentos de todos os dias" (GREIMAS, 2002, p. 75). Nem sempre a experiência estética é fruto de uma graça providencial; ela pode proceder, também, da iniciativa do sujeito e de um trabalho de construção efetuado por ele mesmo.

A semiótica greimasiana está fundamentada na ideia de percepção de sensações, porém, acrescenta-se o caráter inteligível (RAMALHO; OLIVEIRA, 2005). É por meio dessa relação entre o cognitivo e as sensações que o sujeito acessa o mundo. Destarte, a estética não é mais vinculada somente ao belo, mas à estesia, que é a percepção através dos sentidos. A semiótica greimasiana estuda toda e qualquer linguagem e tem por foco a produção e a apreensão de efeitos de sentido. Seu objeto de estudo inicial foi o texto, entendido como objeto de significação, com mecanismos sintáticos e semânticos que respondem pela produção de sentido. Ao buscar apreender os sentidos de um texto, seja verbal, não verbal ou sincrético, a semiótica procura descrever e analisar o que o texto diz e como ele se mostra.

Todo texto possui dois planos, o plano da expressão e o plano do conteúdo, que somente reunidos, em relação à pressuposição recíproca, produzem a significação. O plano da expressão diz respeito ao significante, às qualidades sensíveis do texto: materialidade, disposição no espaço, cores, formas. O plano do conteúdo relaciona-se ao significado, ao discurso produzido numa determinada cultura (PONTES; PILLAR, 2018).

Diante disso, a semiótica procura estudar o problema da significação ou dos sentidos do texto pela análise, em primeiro lugar, do plano do conteúdo, já que, posteriormente, analisa as especificidades da expressão na sua relação com o conteúdo (HERNANDES, 2003). Para compreender o sentido de uma produção textual, a semiótica concebe o seu plano do conteúdo sob a forma de um percurso gerativo. O significado descrito pelo 
percurso gerativo une-se a um plano de expressão para se manifestar. Nesse âmbito, os sentidos de um texto se evidenciam através de um percurso gerativo organizado em três níveis que se inter-relacionam: o fundamental, o narrativo e o discursivo. Em cada um desses níveis há: um componente sintático, que estuda as relações entre os elementos; e um componente semântico, que estuda os conteúdos investidos nas relações sintáticas (PONTES; PILLAR, 2018).

No nível fundamental, o mais simples, pode-se indicar os valores sob os quais o texto está construído, por exemplo, a partir de oposição semântica (vida/morte, natureza/cultura, verdade/mentira). Cada termo oposto recebe uma qualificação semântica e um valor: eufórica positivo/disfórica negativo. Já no nível narrativo se organiza a narratividade, o encadeamento de situações e ações do ponto de vista de um sujeito (REGINALDO; BALDESSAR, 2013). De alguma forma, em alguns casos, um nível pode espelhar o outro.

Nesse sentido, cabe ressaltar que a semiótica se utiliza de dois modelos: o universo individual e o universo coletivo, os quais dão conta das articulações elementares do universo semântico. Esses modelos são constituídos, pois não correspondem a priori à nenhuma realidade sociológica ou psicológica, e seu nível é abstrato, entendido como profundo e não figurativo. No nível figurativo temos uma espécie de estereótipos culturais e, nesses modelos, a universalidade não pode ser comprovada, mas é muitas vezes generalizada, por exemplo, os quatro elementos constitutivos da natureza: fogo, terra, água e ar (RECTOR, 1979).

Assim, a partir desses quatro elementos constitutivos da natureza será feita, neste artigo, a análise da figuratividade das expografias. A figuratividade é um termo/conceito proveniente da teoria estética. Em semiótica significa a semelhança, representação, "imitação do mundo pela disposição das formas numa superfície” (NOGUEIRA, 2007).

Dessarte, a figuratividade estabelece a significação para tudo o que se liga à nossa percepção do mundo exterior (pelos cinco sentidos: visão, tato, olfato, audição e gustação) por meio do discurso (verbal ou não verbal), isto é, articula "propriedades sensíveis" à "propriedades discursivas". Para Greimas (2002, p. 74):

A figuratividade não é mera ornamentação das coisas; é essa tela do parecer cuja virtude consiste em entreabrir, em deixar entrever, em razão de sua imperfeição ou por culpa dela, como que uma possibilidade de além sentido. Os humores do sujeito reencontram, então, a imanência do sensível.

Portanto, neste artigo, buscamos identificar, pela figuratividade das expografias curadas pelos estudantes de licenciatura em Química, a experiência sensível, que 
representa e estabelece uma relação imediata, uma semelhança, uma correspondência entre as figuras semânticas que desfilam sob os olhos do leitor e as figuras do mundo, as quais, na sua experiência sensível, ele experimenta sem cessar.

\section{RESULTADOS E DISCUSSÕES}

Ao final da atividade proposta e detalhada na seção anterior, as pastas/mostras/exposições criadas pelos estudantes no Pinterest foram analisadas e divididas nos dois temas sugeridos inicialmente: abordagem conceitual e abordagem temática. Participaram da atividade 31 estudantes do curso de licenciatura em Química, onde 11 deles seguiram a abordagem conceitual e 20 optaram pela abordagem temática. $\mathrm{Na}$ Tabela 1 estão listados os assuntos escolhidos pelos estudantes exatamente com os nomes elencados por eles próprios e categorizados apenas em abordagem conceitual e abordagem temática.

Tabela 1: Relação das expografias criadas no Pinterest pelos 31 estudantes divididas em abordagem conceitual e abordagem temática.

\begin{tabular}{cc}
\hline Abordagem Conceitual & Abordagem Temática \\
\hline Química Inorgânica & A Química por Trás \\
Química Atomística & Química na Saúde Mente e Corpo \\
Modelos Atômicos & Bioquímica do Corpo Humano \\
Tabela Periódica & Ciência Divertida \\
Tensão Superficial & Química Ambiental \\
Radioquímica & Química de Plásticos \\
Soluções & Química dos Cabelos \\
Química dos Elementos & Agrotóxicos \\
Ligações Químicas (2) & Combustão \\
Introdução às Ligações Químicas & Combustíveis \\
& Conhecendo a Cerveja \\
& Fogos de Artifício \\
Início da Vida na Terra & Metalurgia \\
& Minerais, Rochas e Cristais \\
Mumificação \\
Nanomateriais \\
Estados Físicos da Matéria: coloide ao plasma \\
Princípio da Conservação da Energia \\
Química do Fogo
\end{tabular}

Fonte: Autoria Própria.

É possível constatar, apenas pelo número dos tipos escolhidos pelos estudantes, que a abordagem temática foi muito mais simpática às preferências pessoais. Logicamente que a Química é uma área do conhecimento muito ampla e se estende a muitas outras 
áreas e assuntos tangentes, o que pode ser um dos motivos de preferência por essa abordagem.

Com relação à atividade proposta inicialmente, dos 31, apenas cinco estudantes realmente executaram o exercício seguindo as orientações recomendadas de percorrer as veredas da imaginação, de fazer uma reflexão estética sobre os aspectos sedutores da/na química, sobre as imagens da Química, de se deixar influenciar pelo que a Química nos faz vivenciar, ver, imaginar, suspirar e pelo que nos conta a partir das infografias selecionadas. Realizar uma seleção de imagens com o intuito de contar histórias, expografias, de ter uma narrativa a partir de infografias da Química não pareceu uma tarefa fácil para a grande maioria dos estudantes participantes deste estudo.

A narrativa não envolvia apenas a seleção de imagens de um assunto que se tenha afinidade ou interesse e se fizesse uma compilação a esmo, que resultaria em uma exposição visual sem conexão, com imagens fragmentadas, sem continuidade, harmonia e contexto. Podemos ressaltar a dificuldade dos estudantes em produzir expografias pelo fato de estarem nos semestres iniciais do curso de licenciatura em Química, talvez, pela pouca vivência ou experiência, tenham tido menos referências culturais para executarem a atividade. Também não descartamos falhas nas explicações ou falta de detalhamento, que podem ter comprometido o desenvolvimento da atividade.

As exposições que configuraram narrativas expográficas estão destacadas em negrito na Tabela 1 a partir das abordagens: tensão superficial, química dos elementos, metalurgia, mumificação e princípios da conservação da energia. Outra observação interessante que se pode destacar é que, nessas exposições, os estudantes selecionaram muito mais do que as 20 imagens/infografias, número requerido para a atividade.

A Figura 1 ilustra quatro das cinco $^{4}$ mostras/exposições consideradas como expografias, em que duas trazem a abordagem conceitual da Química e duas envolvem a abordagem temática. O estudante que denominou sua mostra como Elementos Químicos optou por selecionar infografias onde os elementos da tabela periódica são pensados como personagens de mangá, de maneira que cada elemento teria determinados poderes de acordo com suas propriedades; acrescentou, posteriormente, infografias com descrições de propriedades dos elementos químicos. Já a estudante que denominou sua mostra como Mumificação optou por selecionar fotografias e infografias sobre a preservação do corpo humano após a morte em civilizações antigas. Nas imagens selecionadas, apresentou os

\footnotetext{
${ }^{4}$ A quinta expografia não pôde ser analisada, pois o trabalho foi retirado do Pinterest pelo usuário enquanto este artigo estava em elaboração.
} 
sarcófagos, os elementos químicos que eram utilizados no ritual da mumificação, o material utilizado em cada ataúde, a cerimônia em torno dessa atividade, as cores que eram selecionadas para os adornos, entre outras ilustrações que contam uma parte da história dessa época.

O estudante que optou por realizar a atividade sobre o Princípio da Conservação da Energia, além da seleção das imagens/infografias, também deixou uma reflexão sobre sua exposição:

A energia não pode ser criada nem destruída, apenas transformada de uma forma em outra. Conclusão do Princípio da Conservação de Energia. A presente curadoria tem como ideia retratar a conservação e transformação da energia presente nos corpos de animais e plantas ao longo da cadeia alimentar e do seu ciclo de vida. O que você acha que vai acontecer com a energia de seu corpo após sua morte? (extraído da descrição da expografia sobre Princípio da Conservação da Energia).

A partir dessa etapa, ou seja, após serem identificadas as expografias, foi necessário desmembrar o evento para identificar seus componentes e o modo pelo qual cada elemento estaria relacionado a um sistema, com códigos e sintaxe próprios. Além de desmembrar, foi necessário identificar o modo pelo qual a interação entre diferentes sistemas semióticos produz a unidade geral do texto analisado, ou seja, o que faria dele um todo de sentido.

Segundo Greimas (1973,), a semiótica é uma "teoria dos processos de significação" e não uma "ciência dos sistemas de signos", porque considera níveis de interpretação acima e abaixo dos signos. Isso impõe a distinção entre significação e sentido, pois significação é sentido articulado (DIAS, 2016).

Quando nos deparamos com uma expografia e iniciamos um processo de análise figurativa, nos confrontamos com abordagens operacionais, por exemplo, as classes de qualificações que devem ser consideradas como tais e servir para buscar eventuais equivalências dos lexemas ${ }^{5}$ já qualificados. Dessa maneira, conforme sugestão de Rector (1979), estabelecemos as classes de atuantes constituídas de lexemas equivalentes aos quatro elementos constitutivos da natureza: fogo, terra, água e ar.

\footnotetext{
${ }^{5}$ Lexema é o termo-objeto que pertence à língua-objeto e se realiza no discurso, é a unidade mínima do discurso. É o ponto de manifestação e de encontro de semas provenientes de categorias e sistemas sêmicos diferentes, que mantêm entre si relações hierárquicas (RECTOR, 1979).
} 
Figura 1: Captura de tela de quatro mostras/exposições do Pinterest consideradas narrativas.
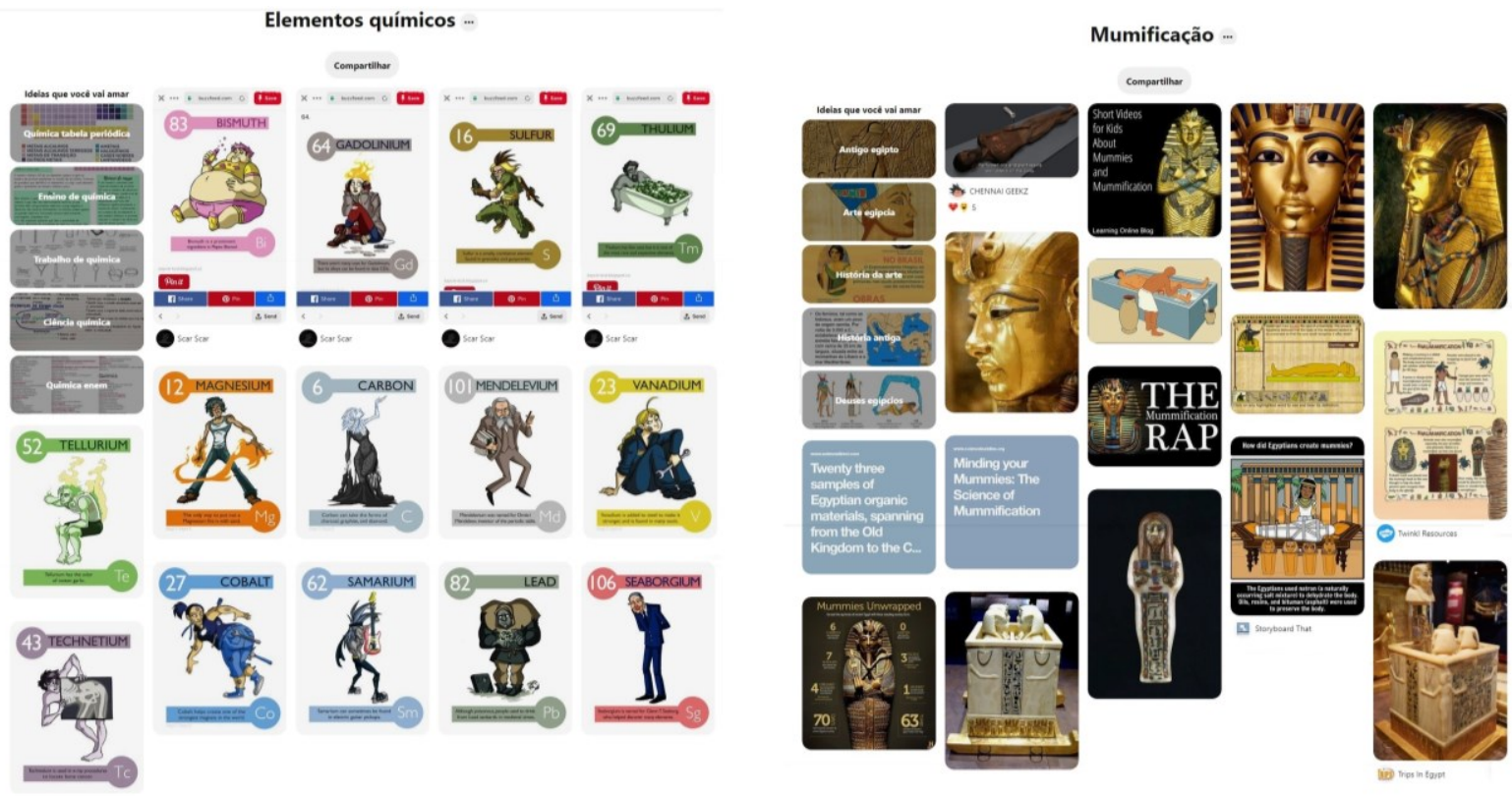

Principio da Conservação de Energia ...
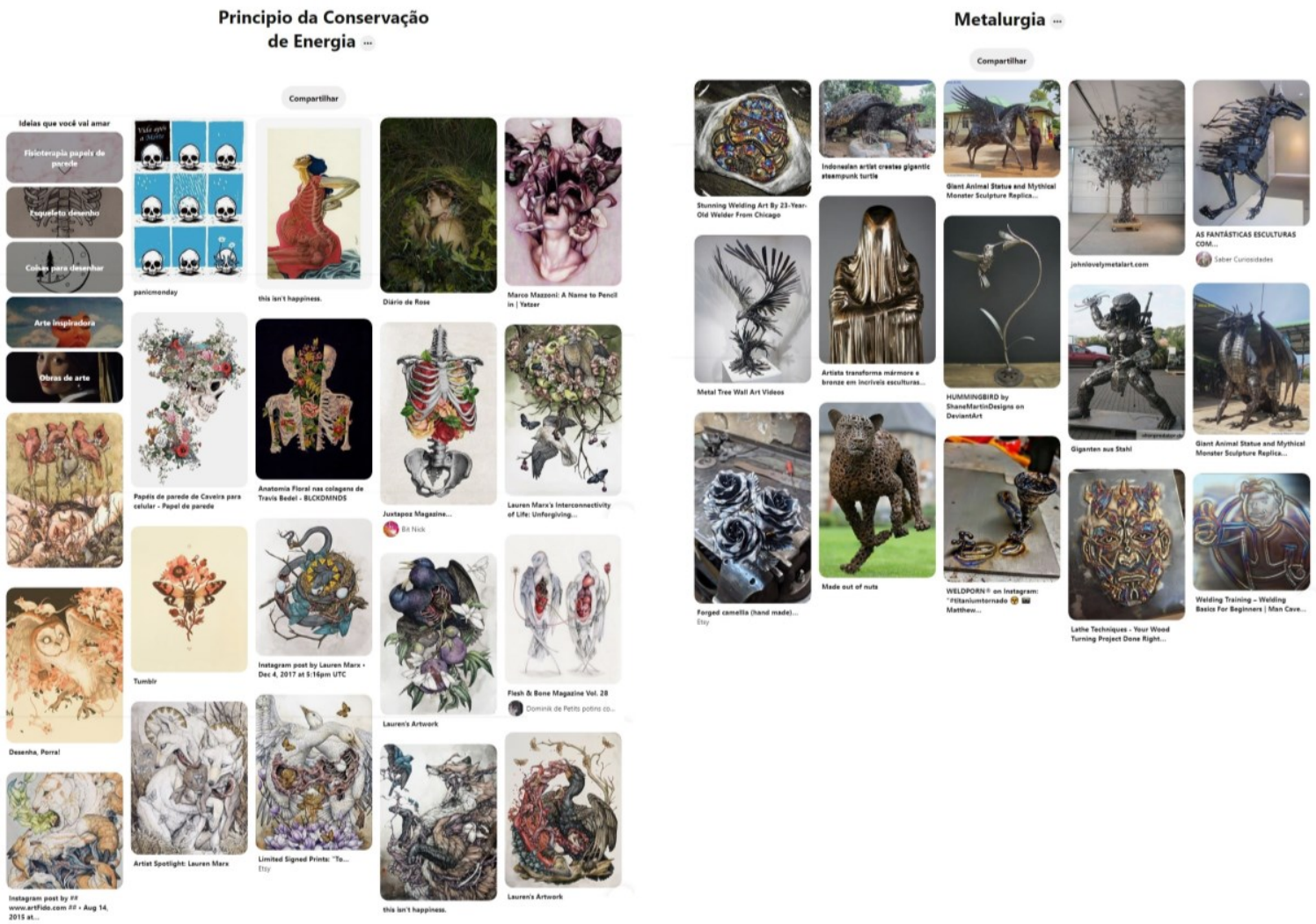

Fonte: Pinterest.

A partir desses quatro elementos, constitutivos da natureza, temos uma espécie de estereótipos culturais que permitiram criar um inventário de qualificações com hierarquia de valores a partir dos elementos elencados na Figura 2. Por exemplo, dos quatro elementos, faremos a redução para duas variantes em oposição, uma dicotomia: vida e morte. Essa 
redução é uma forma operacional de análise textual de Greimas (1973), assim como verdade e mentira são formas dicotômicas.

Figura 2: Universo figurativo.

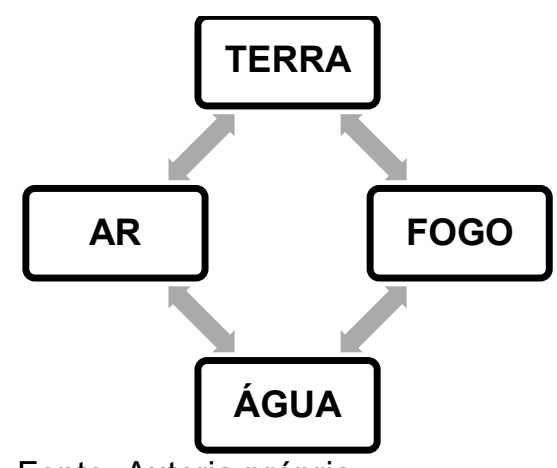

Fonte: Autoria própria.

A Figura 3 ilustra os quatro elementos separados em vida e morte. Por meio de uma série de operações sucessivas de extrações, surgem novas classificações baseadas na oposição vida e morte, por exemplo: a) vida-vivo-criança-sangue-verdade-amor-clarobranco; b) morte-cadáver-velho-doença-mentira-ódio-sombrio-escuro-frio.

Figura 3: Redução dos quatro elementos - água, ar, terra e fogo.

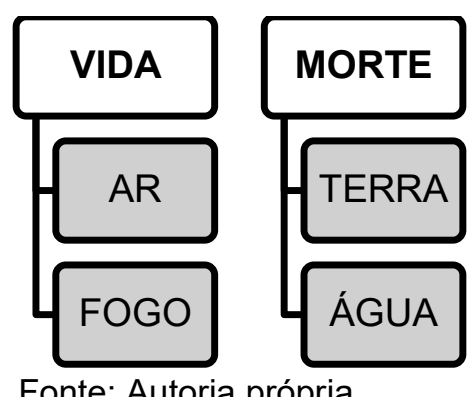

Fonte: Autoria própria.

São assim instituídas uma ordem da vida e uma ordem da morte no processo de extrações sucessivas, com isso, formam um inventário até a saturação do corpus, ou seja, até a última extração. Isso quer dizer que o corpus utilizado para fornecer a extração dos elementos de significação pertencentes à isotopia ${ }^{6}$ de vida e morte, escolhida no início, está esgotado de maneira exaustiva (GREIMAS, 1973). Um corpus é um reagrupamento

\footnotetext{
${ }^{6} \mathrm{~A}$ isotopia, propriedade afeita ao discurso, é um termo emprestado da Física que, semioticamente, significa "a permanência de um efeito de sentido ao longo da cadeia do discurso" (NOGUEIRA, 2007). Numa análise semântica, a isotopia permite observar a permanência e a transformação dos elementos de significação. Ela é responsável pela unicidade de significação de um texto e pela homogeneidade dos significados, garantida, não raro, pela originalidade e pela redundância, isto é, repetição de um número mínimo de signos necessário para a transmissão de uma informação. Além de regras lógicas, a isotopia opera pela coerência semântica (NOGUEIRA, 2007).
} 
estruturado de textos integrais, documentados, eventualmente reunidos e enriquecidos por etiquetagens.

Os corpora não são simples reservatórios ou meros agrupamentos de textos, conquanto sejam constituídos de maneira crítica, pois levam em conta os gêneros e os discursos (RASTIER, 2019). O texto isolado não possui mais existência do que a palavra ou a frases isoladas: para ser produzido e compreendido, ele deve se relacionar a um gênero e a um discurso e esses, por sua vez, a um tipo de prática social.

A Tabela 2 apresenta o inventário de qualificações formado pelas classes vida vs morte. Esse inventário será contraposto às expografias representadas na Figura $1 \mathrm{e}$, por meio de comparação, podemos relacionar as qualificações com as infografias coletadas pelos estudantes.

De acordo com os critérios já apresentados neste texto, as cinco expografias (Figura 1) foram espelhadas no inventário da Tabela 2. A análise ocorre com a comparação das qualificações atribuídas à vida e morte - que equivalem aos quatro elementos constitutivos da natureza (ar, água, fogo e terra). A expografia intitulada Elementos Químicos reúne características voltadas para a classe vida (fogo, ar), como alegria, novo, mobilidade, luz, bem, bom, positivo, forma, brilho, cor. A expografia sobre a Mumificação reúne características voltadas para a classe morte (água, terra), como terra, velho, morte, imobilidade, frio, amorfo, tédio, doença, serpente.

Tabela 2: Inventário de qualificações.

\begin{tabular}{|c|c|c|c|c|c|}
\hline VIDA & vs & MORTE & VIDA & vs & MORTE \\
\hline FOGO & & ÁGUA & ESPERANÇA & & DESESPERO \\
\hline AR & & TERRA & CALOR & & FRIO \\
\hline AMOR & & ÓDIO & LIMPEZA & & SUJEIRA \\
\hline ALEGRIA & & TÉDIO & PUREZA & & PECADO \\
\hline NOVO & & VELHO & VERDADE & & MENTIRA \\
\hline MOBILIDADE & & IMOBILIDADE & BOM & & MAU \\
\hline SAÚDE & & DOENÇA & HUMILDADE & & DESPREZO \\
\hline COELHO & & SERPENTE & COR & & CINZA \\
\hline LUZ & & TREVAS & POSITIVO & & NEGATIVO \\
\hline MUDANÇA & & ESTAGNAÇÃO & FORMA & & AMORFA \\
\hline GASOSIDADE & & LIQUIDEZ & BRILHO & & OPACO \\
\hline BEM & & MAL & SANIDADE & & LOUCURA \\
\hline JUSTIÇA & & INJUSTIÇA & INTEGRAÇÃO & & DESINTEGRAÇÃO \\
\hline
\end{tabular}

Fonte: Greimas (1973, p. 290). 
No caso da expografia sobre Mumificação, a grande parte das características está voltada para a resultante morte, como era de se esperar. A expografia sobre Metalurgia reúne características voltadas para a classe vida (fogo, ar), como brilho, novo, mudança, forma, limpeza. A expografia sobre o Princípio da Conservação da Energia reúne características voltadas para a classe vida (fogo, ar), como cor, luz, mudança, forma. Apesar de as características voltadas para a morte também serem identificadas, o resultado predominante foi na classe vida (fogo, ar).

Das quatro expografias avaliadas, três delas resultaram em características voltadas para a classe vida - que abarca dois elementos constitutivos da natureza, o fogo e o ar - e apenas uma voltou-se para a classe morte. Temos em consideração que essas classificações sobre vida e morte são culturais e dicotômicas. No entanto, o algoritmo dialético aparece como resolução de estruturas de significação, que é incontestavelmente uma das tarefas da semântica, pois as transformações estruturais imaginárias têm papel considerável em todas as espécies de ideologias, individuais ou coletivas, com a ajuda das quais a humanidade justifica o mundo ou programa o futuro.

\section{CONSIDERAÇÕES FINAIS}

Com relação à atividade proposta inicialmente, dos 31, apenas cinco estudantes realmente executaram o exercício e seguiram as orientações recomendadas pela atividade. Realizar uma seleção de imagens com o intuito de contar histórias, expografias, de ter uma narrativa a partir de infografias da química não se constituiu como uma tarefa fácil para a maior parte dos estudantes de Química.

A Química é uma área do conhecimento baseada, em muitos aspectos, na percepção: cor, odor, textura etc. A percepção não é um lugar linguístico onde se situa a apreensão da significação, "o semiológico é apreensível dentro da percepção" (GREIMAS, 1973, p. 15). A sensação se refere aos cinco sentidos (tato, visão, audição, paladar e olfato), enquanto a percepção é a síntese promovida pela atividade mental. Greimas (2002) se afasta do conceito de estética vinculado ao belo e se aproxima da estética como estesia (percepção por meio dos sentidos, do mundo exterior), como experiência do prazer, das percepções dos sentidos, da sensualidade e da sensibilidade. Afirma 0 autor: "cognitivamente inapreensível" ao se referir ao acidente estésico (GREIMAS, 2002, p. 26). O termo "fratura" significa um acidente estético, constitui uma ruptura de isotopia, um "relâmpago passageiro na cotidianidade" (GREIMAS, 2002, p. 26); um momento em que, fugindo à lógica do intelectualismo, propõe-se o inesperado da imperfeição: a estesia. 
Dessa forma, entendemos que é preciso dar mais atenção às questões estéticas e estésicas para entender como as descobertas químicas são feitas, para melhor ensinar e aprender sobre os conhecimentos e conteúdos da área. Há quem sustente a ideia de que os alunos são prejudicados ao se esconder a face sedutora e estética das disciplinas científicas, pois, sem ela, não há motivação ou atração sobre o assunto (ROOTBERNSTEIN, 1996). Mas os estudantes devem saber que muitos químicos exímios e bemsucedidos descrevem a ciência como uma arte e que as considerações estéticas podem motivar não apenas um interesse na química, mas em problemas e soluções (ROOTBERNSTEIN, 2003).

O acidente estético, estesia, uma experiência do prazer, pode ocorrer em diversas situações cotidianas, até mesmo em nossas horas de trabalho ou ao navegar na internet. Hoje em dia, as pessoas têm uma infinidade de fontes de conteúdo digitais à disposição para refinamento e reaproveitamento. Ser capaz de exercer a curadoria, em quantidades enormes de informação digital, compilar, analisar e recomendar, tem se estabelecido como uma competência básica para atuação na sociedade tecnológica atual.

Curiosamente, a mudança social pode ser instigada pela curadoria digital no sentido de envolver e apoiar instituições de ensino nessa mudança e, nesse sentido, é também apresentada como uma competência básica para os processos de ensino e aprendizagem, sendo que, na escola, o professor é, em primeiro plano, um organizador que tem engajamento e envolvimento. A curadoria já se faz nas salas de aula há décadas, sob determinados aspectos, mas atualmente incorporam-se à discussão abordagens críticas, o viés e o panorama da informação.

Curadoria é o que fazemos em nossos laptops, tablets e telefones, em nossas redes sociais e navegadores e é uma tarefa que prossegue ao longo da vida. Regularmente nos atualizamos, reciclamos, reagrupamos, revemos nossas fontes de informação, nossos aplicativos (ao instalar uns e desinstalar outros, que caíram na obsolescência tecnológica). Não obstante, entende-se que internet é muito dinâmica e o que nos serve agora daqui um tempo pode não ser mais útil. Tal conhecimento, portanto, pode auxiliar estudantes na curadoria educacional. Nós, professores e educadores, devemos estar um passo à frente, adiantados ou no mesmo nível de bagagem digital e tecnológica que os alunos possuem, para que possamos auxiliar e atuar na curadoria educacional. Das ferramentas disponíveis e de livre acesso na internet, que podem auxiliar no processo curatorial, o Pinterest, plataforma estritamente visual, se mostrou como uma possibilidade de criação e compartilhamento de imagens. 
Por fim, renovamos nosso convite aos professores de Química em vista de propiciar aos estudantes a experiência estética do cotidiano, promovida pela estesia relacionada à visualização de imagens de e sobre a Química. Que nossa Ciência possa ser, também, a fuga momentânea e efêmera de distrair-se do tédio, que ela nos auxilie por meio dos privilégios da estesia e na poetização da vida cotidiana.

\section{REFERÊNCIAS}

ALVES, Rubem. A escola com que sempre sonhei sem imaginar que pudesse existir. São Paulo: Papirus 7 Mares, 2001.

ARTHUR, William B. The Nature of Technology: what it is and how it evolves. Londres: Penguin, 2009.

ASLAM, Salman. Pinterest by the Numbers: Stats, Demographics \& Fun Facts. Omnicore, 2021. Disponível em: https://www.omnicoreagency.com/pinterest-statistics/. Acesso em: 24 de maio de 2021.

BARTLETT, Jamie; MILLER, Carl. Truth, lies and the internet: a report into young people's digital fluency. Londres: Demos, 2011.

BHASKAR, Michael. Curadoria: O poder da seleção no mundo do excesso. São Paulo: Edições SESC, 2020.

CORREIA, Ana-Paula. As Múltiplas Facetas da Curadoria de Conteúdos Digitais. ReDoC - Revista Docência e Cibercultura, v. 2, n. 3, p. 14-32, 2018.

CORTELLA, Mario S.; DIMENSTEIN, Gilberto. A Era da Curadoria: o que importa é saber o que importa. São Paulo: Papirus 7 Mares, 2015.

DIAS, Álvaro R. A aplicação da semiótica discursiva na análise da comunicação publicitária para a divulgação da marca. Intexto, n. 37, p. 394-412, 2016.

EICHLER, Tatiana Z. N.; EICHLER, Marcelo L. A rede social Pinterest e a curadoria na educação científica: O exemplo do surrealismo de Dalí. In: ENCONTRO NACIONAL DE PESQUISA EM EDUCAÇÃO EM CIÊNCIAS, Anais do XI ENPEC, Florianópolis, 2017.

EICHLER, Tatiana Z. N.; ARAÚJO, lone C.; EICHLER, Marcelo L. A curadoria no Pinterest como transcriação da representação e do imaginário acerca do átomo. RENOTE - Revista Novas Tecnologias na Educação, v. 15, n. 1, p. 1-13, 2017.

FERREIRA, Aurélio Buarque de Holanda. Dicionário Aurélio da Língua Portuguesa. São Paulo: Editora Positivo, 2008.

FERRER, Raquel H. Gráficos que cuentan historias: caracterización de infografías y visualizaciones narrativas a través de Pinterest. Obra Digital, n. 9, p. 98-119, 2015.

FLORIDI, Luciano. Semantic Capital: Its Nature, Value, and Curation. Philosophy \& Technology, v. 31, p. 481-497, 2018. 
GARCIA, Marilene S. dos Santos; CZESZAK, Wanderlucy. Caminhos para a prática da curadoria educacional. Pátio, n. 88, p. 22-25, 2019a.

GARCIA, Marilene S. dos Santos; CZESZAK, Wanderlucy. Curadoria Educacional:

Práticas pedagógicas para tratar (o excesso de) informação e fake news em sala de aula.

São Paulo: SENAC, 2019b.

GREIMAS, Aljirdas. Semântica Estrutural. São Paulo: Editora Cultrix, 1973.

GREIMAS, Aljirdas. Da Imperfeição. São Paulo: Hacker Editores, 2002.

HARARI, Yuval N. Sapiens: Uma Breve História da Humanidade. São Paulo: L\&PM, 2018.

HERNANDES, Nilton. Análise de Publicidade da revista Veja. Cadernos de Semitótica Aplicada, v. 1, n. 2, p. 25-43, 2003.

KIILI, Carita; LAURINEN, Leena, MARTTUNEN, Miika. Students evaluating internet sources: from versatile evaluators to uncritical readers. Journal of Educational Computing Research, v. 39, n. 1, p. 75-95, 2008.

LANDOWSKI, Eric. Com Greimas. São Paulo: Estação das Letras e Cores, 2017.

LANDOWSKI, Eric; DORRA, Raul; OLIVEIRA, Ana Cláudia. Semiótica, estesis, estética. São Paulo: EDUC, 1999.

MARTINEZ, Elisa de Souza. Curadoria e expografia em abordagem semiótica. In: ENCONTRO NACIONAL DA ASSOCIAÇÃO NACIONAL DE PESQUISADORES DE ARTES PLÁSTICAS DINÂMICAS EPISTEMOLÓGICAS EM ARTES VISUAIS, Anais [...], Florianópolis, 2007.

MAYER-SCHÖNBERGER, Viktor; CUKIER, Kenneth. Big Data: Como extrair volume, variedade, velocidade e valor da avalanche de informação cotidiana. São Paulo: Campus, 2013.

NEVES, Sandra G. A Produção Omnilateral do Homem na Perspectiva Marxista: a Educação e o Trabalho. In: CONGRESSO NACIONAL DE EDUCAÇÃO, Anais [...], Curitiba, 2009.

NOGUEIRA, Fernanda F. M. Isotopia temática e figuratividade em "Eis os amantes" e "Introdução" de Augusto de Campos. Estudos Semióticos, n. 3, p. 1-12, 2007.

PONTES, Gilvânia M. D. de; PILLAR, Analice D. Experiência Estética na Semiótica Discursiva: pistas para leitura de textos de professores sobre suas práticas. Palíndromo, v. 10 , n. 22 , p. 12-24, 2018.

RAMALHO E OLIVEIRA, S. R. Imagem também se lê. São Paulo: Edições Rosari. 2005.

RASTIER, François. Da semântica estrutural à semiótica das culturas. Galaxia, Especial 2 Dossiê Algirdas J. Greimas, p. 15-40, 2019.

RECTOR, Monica. Para Ler Greimas. Rio de Janeiro: Francisco Alves, 1979. 
REGINALDO, Thiago; BALDESSAR, Maria José. Teoria Educacional e Semiótica na

Compreensão de Imagens: análise da animação "Um Plano Para Salvar O Planeta". In: VI SEMINÁRIO LEITURA DE IMAGENS PARA A EDUCAÇÃO: MÚLTIPLAS MÍDIAS, Anais [...], Florianópolis, 2013.

ROOT-BERNSTEIN, Robert. Do we have the structure of DNA right? Art Journal, v. 55, n. 1, p. 47-55, 1996.

ROOT-BERNSTEIN, Robert. Sensual Chemistry. HYLE - International Journal for Philosophy of Chemistry, v. 9, n. 1, p. 33-50, 2003.

SANTAELLA, Lúcia. Estética: de Platão à Peirce. São Paulo: Experimento, 1994.

SCHAFF, Adam. A Sociedade Informática. São Paulo: Brasiliense, 1992.

SCHUBERT, Karsten. The Curator's Egg: The Evolution of the Museum Concept from the French Revolution to the Present Day. Londres: One-off Press, 2000.

WALLMAN, James. Stuffocation: Living More with Less. Londres: Penguin, 2015. 


\section{ANEXOS}

Links das expografias do Pinterest realizadas pelos estudantes.

\begin{tabular}{|c|c|}
\hline Tema & Link \\
\hline A química dos plásticos & $\begin{array}{l}\text { https://br.pinterest.com/aanjos0646/a- } \\
\text { qu\%C3\%ADmica-dos-pl\%C3\%A1sticos/ }\end{array}$ \\
\hline $\begin{array}{l}\text { A química e os cabelos: } \\
\text { gerando conhecimento }\end{array}$ & $\begin{array}{l}\text { https://br.pinterest.com/calvetedarocha/a- } \\
\text { qu\%C3\%ADmica-e-os-cabelos-gerando- } \\
\text { conhecimento/ }\end{array}$ \\
\hline A Química Orgânica por trás... & https://pin.it/4Bg8K11 \\
\hline Agrotóxicos & https://pin.it/gxsrk4m2vdvlbv \\
\hline Bioquímica do Corpo Humano & $\begin{array}{l}\text { https://br.pinterest.com/marianagw99/bioqu \%C3\%AD } \\
\text { mica-corpo-humano/ }\end{array}$ \\
\hline Ciência Divertida & https://pin.it/5LMDyDC \\
\hline Combustão & https://pin.it/zakebaqj3kqkxx \\
\hline Combustíveis & https://pin.it/kgmhzpyci2aheb \\
\hline Conhecendo a cerveja & $\begin{array}{l}\text { https://br.pinterest.com/tayanebrigidi/conhecendo-a- } \\
\text { cerveja/ }\end{array}$ \\
\hline Elementos Químicos & https://pin.it/4it6HBi \\
\hline Fogos de artifício & https://pin.it/2cz|4tk5segutb \\
\hline Início da vida na Terra & $\begin{array}{l}\text { https://br.pinterest.com/lkochem/in\%C3\%ADcio-da- } \\
\text { vida-na-terra/ }\end{array}$ \\
\hline Introdução às ligações químicas & $\begin{array}{l}\text { https://br.pinterest.com/giovani 2858/curadoria-de- } \\
\text { imagens-da-qu\%C3\%ADmica-no-pinterest/ }\end{array}$ \\
\hline Ligações Químicas & https://pin.it/3bcjmZA \\
\hline Ligações Químicas & https://pin.it/2J35y8I \\
\hline Metalurgia & https://br.pinterest.com/matheusbrogni/metalurgia/ \\
\hline Minerais, rochas e cristais & $\begin{array}{l}\text { https://br.pinterest.com/fmaciel016/curadoria- } \\
\text { espa\%C3\%A7os-escolares/ }\end{array}$ \\
\hline Modelos Atômicos & $\begin{array}{l}\text { https://br.pinterest.com/debritodesouza/modelos- } \\
\text { at\%C3\%B4micos/ }\end{array}$ \\
\hline Mumificação & $\begin{array}{l}\text { https://br.pinterest.com/tecn clvt/mumifica\%C3\%A7\% } \\
\text { C3\%A3o/ }\end{array}$ \\
\hline Nanomateriais & $\begin{array}{l}\text { https://br.pinterest.com/josedanielsouza/nanomateriai } \\
\text { s/ }\end{array}$ \\
\hline $\begin{array}{l}\text { Os Estados Físicos da Matéria, } \\
\text { Colóide ao Plasma }\end{array}$ & https://pin.it/nnx4lv6b55bcq3 \\
\hline $\begin{array}{l}\text { Princípio da conservação de } \\
\text { energia }\end{array}$ & $\begin{array}{l}\text { https://br.pinterest.com/pedro vontobel/1a-lei-da- } \\
\text { termodin\%C3\%A2mica/ }\end{array}$ \\
\hline Química Ambiental & https://pin.it/1Tlu0iL \\
\hline Química Atomística & $\begin{array}{l}\text { https://br.pinterest.com/marianagw99/qu\%C3\%ADmic } \\
\text { a-atom\%C3\%ADstica/ }\end{array}$ \\
\hline Química do fogo! & https://pin.it/pb6s64i2gf3xwv \\
\hline $\begin{array}{l}\text { Química na Saúde, mente e } \\
\text { corpo }\end{array}$ & $\begin{array}{l}\text { https://br.pinterest.com/cinthia clemente/qu\%C3\%AD } \\
\text { mica-na-sa\%C3\%BAde-mente-e-corpo/ }\end{array}$ \\
\hline Química nos alimentos & https://pin.it/gofbrm3qw7vdy4 \\
\hline Radioatividade & https://br.pinterest.com/jucelainepolett/radioatividade/ \\
\hline Soluções químicas & https://pin.it/zshciplp3vyfxr \\
\hline
\end{tabular}




\begin{tabular}{|l|l|}
\hline Tabela Periódica & $\begin{array}{l}\text { https://br.pinterest.com/luiss311999/tabela- } \\
\text { peri\%C3\%B3dica/?invite code=fccbd76d4b014185b4 } \\
\text { b00073d67a8101\&sender=780952529042321548 }\end{array}$ \\
\hline Tensão Superficial & $\begin{array}{l}\text { https://br.pinterest.com/cassiana2336/tens\%C3\%A30 } \\
\text {-superficial-ensino-de-qu\%C3\%ADmica/ }\end{array}$ \\
\hline
\end{tabular}

